\title{
Analysis on Problems and Countermeasures in Sports Dance Teaching in Colleges and Universities
}

\author{
Yan $\mathrm{Xu}^{1}$ \\ ${ }^{1}$ Chengdu Medical College, Chengdu, Sichuan Province, China
}

Keywords: colleges and universities; sports dance teaching; problems; countermeasures

\begin{abstract}
Sports dance teaching in colleges and universities plays an important role in cultivating college students' communicative competence and strong physical fitness. This paper focuses on analyzing the significant problems existing in current sports dance teaching. Based on the systematic analysis of specific problems, this paper deeply explores the effective solutions so that the comprehensive improvement in the performance of sports dance teaching in colleges and universities can be finally achieved.
\end{abstract}

\section{Introduction}

From the current social perspective, the fast-paced life makes people face more and more pressure. In addition, the open society is more cooperative. Thus, the students should have a healthy body and strong communication skills, which is of great significance for their future development. The sports dance teaching in colleges and universities not only has the function of strengthening physical fitness, but also plays the role of cultivating communicative competence. Therefore, it is of great practical significance to scientifically and systematically analyze the problems existing in sports dance teaching in colleges and universities and analyze the specific problem-solving strategies.

\section{The Necessity and Importance of College Sports Dance Teaching}

It is necessary to carry out the sports dance teaching in colleges and universities nowadays. The necessity is mainly reflected in the following three aspects. Firstly, the current society is no longer a single era. Teamwork is required both in project construction and in scientific research in colleges and universities. Thus, the students' teamwork skills need to be strengthened. Many college students at this stage are from one-child families. This kind of family environment has had an important influence on them. There is not a universal awareness of cooperation among college students with one-child families. Therefore, the development of sports dance teaching is of great significance for college students' cooperation awareness. Secondly, the development of various industries in the society requires a general increase in the importance of information communication. College students must have a strong communication awareness and communication concept. Therefore, sports dance teaching is necessary in the cultivation of exchange consciousness and ideas of college students. necessity. Thirdly, the fast-paced life and work have generally increased the pressure people face. Under such circumstances, a strong body can be better able to resist pressure. It is necessary for college dance teaching to achieve physical fitness and enhance the pressure resistance.

The importance of sports dance teaching in colleges and universities is mainly reflected in the following two aspects. Firstly, as far as students are concerned, sports dance teaching cannot only help students improve their communicative competence, but also improve their physical health. In specific learning, students also can be improved in other areas. Therefore, sports dance teaching in colleges and universities has important significance on enhancing their overall abilities. Secondly, for schools, the continuous advancement of college education and teaching can improve the overall teaching performance of colleges and universities. The education and teaching of colleges and universities covers many categories. The progress of teaching in all categories plays an important role in the improvement of college teaching quality and its fame. Although physical dance teaching is not 
the mainstream of college education, it is still an important component. Therefore, promoting the teaching of sports dance education in colleges and universities is of great significance to the development of the school.

\section{Problems in College Sports Dance Teaching}

Through the analysis of the current situation of the development of college sports dance teaching, we can find that there are several outstanding problems in the specific teaching. Careful analysis of these major issues has positive guiding significance for better understanding of the current status of physical dance teaching and improving teaching methods.

\subsection{Fewer teaching materials for college sports dance teaching.}

The most prominent problem in the current sports dance teaching in colleges and universities is that there are fewer teaching materials available. In the education and teaching of colleges and universities, teaching materials are important tools and means of communication. On the one hand, the teaching materials are specific and systematic and it stipulates specific curriculum training objectives. On the other hand, the selection of teaching materials is scientific and it has important guiding significance for students' ability training in all aspects. However, in the current college sports dance teaching, there are few textbooks available, which leads to the lack of direction and goal of the whole teaching. The teachers' specific teaching strategy and students' learning will show confusion. Few available teaching materials and few teaching contents can be referred to will lead to the incomplete implementation of teaching in the specific teaching. Therefore, there has been a single and one-sided situation in sports dance teaching in colleges and universities. In short, the lack of teaching materials in sports dance teaching in colleges and universities has seriously affected the overall development of education.

\subsection{Weak content-oriented design of sports dance teaching in colleges and universities.}

Another outstanding problem in the dance teaching of college sports is that the targeted design of dance teaching content is weak. From the perspective of educational practice analysis, although the ultimate goal of sports dance teaching is to cultivate students' communicative competence and exercise their own physique, different content settings can also cultivate their other abilities in specific teaching practice. For example, solo dance can cultivate students' self-confidence and group dance can cultivate students' cooperative ability. As far as the specific teaching analysis is concerned, different students in the classroom practice will show different traits, that is to say, they will show differences in their abilities. For these differences, college teachers can make targeted and practical teaching. Designed to help students develop and enhance their abilities in all aspects, the overall effectiveness of teaching should be enhanced as a whole. However, in the teaching of sports dance in colleges and universities, teachers pay more attention to the integrity of teaching design, leading to the teaching design only focusing on the basic training of students and neglecting the cultivation of comprehensive ability of college students. At the same time, the universal teaching design will also result in more significant waste of resources, which is also very unfavorable for teaching cost control.

\subsection{The imperfect infrastructure construction of sports dance teaching in colleges and universities.}

The current infrastructure of sports dance teaching in colleges and universities needs to be improved. From the practice analysis of education and teaching, hardware and software facilities have a great role in promoting education. Perfect and advanced education and teaching facilities can positively and effectively promote the implementation of specific teaching, which can promote the quality of college sports dance teaching. In sports dance teaching, there are also serious lacks of auxiliary equipment and facilities for dance teaching, which affects the improvement of the interest in education and the development of rich content. At the same time, in the teaching of dance education in colleges and universities, there are obvious lags in the use of specific teaching methods and techniques, so the efficiency and quality of the overall teaching is difficult to improve. In short, the 
weak infrastructure and lack of physical education dance teaching in colleges and universities have seriously hindered the comprehensive function of college education teaching, seriously affecting the overall quality of teaching and the realization of teaching effects in colleges and universities.

\subsection{Prominent problems in college sports dance course system.}

The problem of the sports dance course system is one of the most prominent problems in the current college sports dance teaching. In the practice of sports dance teaching in colleges and universities, most universities place the core of sports dance teaching in practical training. Therefore, in the construction of the entire specific course system, they are closely related to practical training. It is true that training is the core of sports dance teaching. However, theory is also something that cannot be ignored. In the specific teaching, the content shown in dance, such as how to show it, the safety protection and so on, all need theoretical support. If it is out of the theory, the professionalism and safety of sports dance teaching will be difficult to obtain effective protection. Therefore, based on the specific content of this aspect, colleges and universities need to make different proportions of the training courses and theoretical courses while designing the curriculum system and combine them to change the current training, contributing to the outstanding application effect.

\section{Effective Countermeasures to Solve the Problems in College Sports Dance Teaching}

\subsection{To deepen curriculum research and promote the rich and professional development of teaching materials.}

Firstly, to solve the problems in college sports dance teaching, the necessary measures are to deepen the study of the curriculum and promote the enrichment and professional development of the teaching materials. In the specific teaching, the teaching materials are the important guidance and reference for teaching. Due to the lack of teaching materials, especially no corresponding teaching material, the specific teaching cannot be constructed systematically. In view of this situation, colleges and universities need to actively summarize their own practice of sports dance teaching, analyze the content and purpose of practical teaching and compare the comprehensive training outline of college students, so that they can judge whether the teaching material is scientific. Through continuous practice summarization, colleges and universities can clearly analyze the objectives and content of college sports dance teaching and actively provide ideas for the preparation of teaching materials. Of course, the ideas that only single school can provide are unitary. Therefore, from the perspective of sports dance teaching analysis, college unions should be formed so that they can determine the specific content of teaching materials based on the specific practices of each school and realize the richness and professionalism of textbook writing. Therefore, through the study and practice of the entire university sports dance curriculum, it makes clear judgment on the specific content and goals of sports dance teaching and realizes the richness and unique professionalism of sports dance teaching in colleges and universities.

\subsection{To adhere to the people-oriented principle and do targeted teaching design for the cultivation of students' quality.}

As far as the analysis of sports dance teaching in colleges and universities is concerned, the second important content of specific problem solving is to make targeted instructional design for students' quality training. The development of any course requires the design of teaching. The better the scientific design of the teaching, the more prominent the execution of the course and the more obvious the specific classroom effect will be. From the specific analysis of the current curriculum teaching, sports dance teaching in colleges and universities has its own value and tasks. And the specific teaching content is also targeted for the quality training of students. For example, group dance teaching is mainly to cultivate students' cooperation ability; choreography teaching trains students' innovative ability and basic combination ability. Thus, different teaching content arrangements will have different effects. Based on this situation, in the specific teaching design, specific design must be done according to the specific situation of the students, so that the value of 
teaching can be maximized. All in all, teachers need to do specific analysis and summary of students' performance in the implementation of specific teaching, so that in the subsequent teaching, specific content design can be made for students' differences and the teaching and the development of students' adaptability will be stronger.

\subsection{To keep pace with the times and improve the construction of physical dance teaching facilities in colleges and universities.}

Because the current sports dance teaching in colleges and universities has obvious imperfect facilities, they should make comprehensive improvement of the specific teaching infrastructure construction. In terms of the improvement of college sports dance facilities, colleges and universities should focus on the following two aspects. First, to actively analyze the equipment and facilities needed for sports dance teaching, including the types, functions and performances of equipment in sports dance teaching, as well as more clear information for the procurement of sports dance facilities. Second, to carry out specific equipment procurement for college sports dance facilities. The facilities and equipment that need to be used in the specific teaching are selected based on their performance and role. And the facilities and equipment with higher cost performance are used in specific teaching. From the point of view of teaching practice, after perfecting the facilities and equipment, the overall teaching form will be enriched; the students' learning interest and the overall level of teaching will be greatly improved. Therefore, in sports dance teaching in colleges and universities, facilities are important auxiliary equipment for teaching. They should be well-constructed and optimized and the basic conditions for teaching should be improved, so that the effect of sports dance teaching in colleges and universities will be significantly improved.

\subsection{To improve the construction of sports dance course in colleges and universities and promote the scientific development of education and teaching.}

While continuously solving the problems in college sports dance teaching, the most important measure is to adjust the curriculum system so as to promote the scientific development of education and teaching. Although sports dance teaching is a course with more significant training, the application of the theory needs to be emphasized in the specific training process. Because some basic theories are of great importance in the safety improvement of dance training. For example, the coordination and safety of limb parts in dance training and the protection of limb joints in specific training need to be achieved through theoretical reinforcement. Based on this situation, in the specific teaching, colleges and teachers need to adjust the teaching system according to the specific course content in order to achieve the overall teaching practice and theory interspersed and improve the efficiency, quality and safety of sports dance teaching in colleges and universities. Therefore, through the adjustment of sports dance teaching in colleges and universities curriculum system, the scientific development of education and teaching can be achieved, which contributes to the overall level of teaching is also conducive to the enrichment and development of students' practice and theory learning.

The dance teaching plays an important role in the improvement and progress of the overall teaching quality in colleges and universities. It also plays an important role in the cultivation and promotion of students' abilities. Therefore, we must attach importance to the important role of college sports dance teaching. By analyzing the significant problems in the current education and teaching and discussing the specific solutions to the problems, we can more clearly understand the current situation of education and teaching and point out clearer development path for the progress of education and teaching. Therefore, it is of great practical significance to pay attention to the analysis of the problem and discuss the specific solution strategies for the development of sports dance teaching in colleges and universities.

\section{References}

[1] J. J. Mei, X. Li. Analysis on the Problems and Countermeasures in College Sports Dance Teaching [J].Youth times, 2016 (13): 225-225. 
[2] D. F. Qian, L. H. Zhou. Problems and Countermeasures in the Teaching of College Sports Dance [J].Sports Time, 2016 (19).

[3] L. Zheng. Analysis on the Current Situation and Countermeasures of the Development of College Sports Dance Clubs in China [J]. Testing and Evaluation, 2017 (1).

[4] L. X. Ouyang. Problems and Strategies in Sports Dance Education in Colleges and Universities [J]. Song of the Yellow River, 2017 (1): 44-44.

[5] J. C. Zheng, Y. Liu, N. Zhao, et al. Investigation and Research on the Current Situation of College Public Sports Dance Teaching___Taking Wuxi Taihu College as an Example [J]. Journal of Wuxi Institute of Technology, 2016, 15 (4): 45-48. 